\title{
Income in Retirement
}

\author{
Geoff Rashbrooke
}

Most working-age people in modern industrial societies principally manage their finances by reference to their direct and regular income from their employment. This suggests that when they move into retirement, the large majority (but not necessarily all) would feel most comfortable in continuing to have a significant degree of regular income, preferably commensurate with their income pre-retirement.

Policy in New Zealand on retirement income from 1992 up until recently has had two main features:

- New Zealand Superannuation, providing a flat-rate, residence-based pension at about 32\% of national average earnings for each member of a married couple and $39 \%$ of national average earnings for a person living alone; and

- government support for financial education through the office of the Retirement Commissioner, with the objective that New Zealanders will be equipped to plan for their retirement and know how to save sufficient to maintain their pre-retirement standard of living through into retirement, should they so choose.

As a crude rule of thumb, it is often stated that people wanting to maintain living standards into retirement should plan for income in retirement at a level of $70-75 \%$ of their pre-retirement income, reflecting lower costs (such as not needing to travel to work, or having acquired durables or provided for the future purchase thereof, etc). ${ }^{1}$ But New Zealand Superannuation on its own will fall well short for many people in meeting a 70-75\% replacement rate target, even those on average incomes. ${ }^{2}$

In the past, but to an increasingly lesser extent now, some people could expect a pension from their employer's pension scheme, particularly those who worked most of their lives for the government, or for large organisations such as banks, insurance companies and petrol companies. However, as the result of reforms in the late 1980s, most notably the removal of a special tax treatment that had recognised occupational pensions as deferred pay, such pension schemes have mostly either wound up, been converted to defined contribution and/ or closed to new entrants. ${ }^{3}$

Of course, a number of people will not have assets over and above what they want to keep by way of precautionary savings and/or for bequests. Some people may have needs met by family on a regular basis and hence have less call for cash income. But for those who have accumulated 'excess' assets, practical ways to decumulate them - i.e. convert them into a regular income - presents an issue not as yet high on the retirement income policy agenda. (One might add that the introduction of KiwiSaver ${ }^{4}$ in the 2005 Budget, and particularly the enhanced version announced in the 2007 Budget, makes it likely that many more working people will arrive at retirement with financial assets to supplement their retirement income from New Zealand Superannuation.)

The current position in New Zealand is that obtaining regular supplementary income in retirement from accumulated retirement assets will, in the absence of any change, rely principally on either the drawing down of those assets in a structured fashion, or the purchase of an annuity from a life insurance office.

1 See, for example, Munnell and Soto (2005). These are in respect of gross incomes.

2 Note that a full discussion of replacement rates should take into account living arrangements (i.e. whether a person is partnered or living alone) and housing arrangements (i.e. whether mortgage-free or paying rent).

3 Currently the average 'in-force' pension per capita in the $65+$ age group is about $\$ 1,400$ per annum. By 2050 , in the absence of any policy change, the author estimates that this will fall to about $\$ 65$ per annum, as the result of a fall in in-force pensions compounded by increased numbers of persons 65 and over.

4 KiwiSaver is an auto-enrolment-based, national, defined contribution savings scheme, introduced in response to observed negative household savings rates and falling coverage of occupational retirement schemes. KiwiSaver has certain capped incentives, and will provide lump sums at age 65 . 
The differences and similarities between annuitisation and draw down

Draw down is the process of determining what regular amount one can take out of one's savings over a fixed period so that the money (including investment return from the diminishing capital) runs out at a fixed point, usually set as one's expectation of life. Annuitisation is applying the savings in the purchase of an annuity, conventionally from a life insurance company; the provider guarantees to pay you a regular amount for as long as you live.

In both cases an assessment has to be made of the investment return over the likely period of the payments. In the case of draw down, this is needed to calculate the regular payments to be taken over the given predetermined period. For an annuity, the expected return is one of the main factors used to calculate the annuity payment, the others being mortality and expenses.

A person utilising draw down may insulate themselves to some extent against investment risk by investing in fixed interest bonds of appropriate dates, or in a guaranteed
Expenses also arise in both cases. Investment management fees are likely to be incurred, as well as transaction costs of various kinds, including advisor fees and/or commissions in the case of draw down. Some people utilising draw down may do their own calculations and their own investment, but it can be risky without the appropriate skills, and in Australia professional advice on draw down is widespread. It appears a priori likely that annuity provision will usually incur lower direct costs.

Under draw down, death earlier than expected causes an unintended bequest to the estate. Death later than expected will leave the person with no income. Under annuitisation, there is protection for as long as one lives - but on early death, at least under conventional annuity contracts, there is no refund.

To summarise, the principal differences then are the flexibility inherent in draw down (since one has access to one's capital), and the guarantee for life inherent in annuitisation. The following schematic was proposed by a reader of an earlier draft of this article, Andrei Andreianov, to summarise the differences between draw down and the longevity insurance that is the key characteristic of annuitisation.

Table 1: Contrast of longevity insurance and draw down

\begin{tabular}{|l|l|l|}
\hline & Early death & Prolonged life \\
\hline Longevity insurance & $\begin{array}{l}\text { Benefit goes to other participants in } \\
\text { the insured pool }\end{array}$ & $\begin{array}{l}\text { Participant benefits through } \\
\text { maintained income }\end{array}$ \\
\hline Draw down & Benefit goes to the heirs & $\begin{array}{l}\text { Family or children needed to provide } \\
\text { support }\end{array}$ \\
\hline
\end{tabular}

return fund. The annuity provider, because they are guaranteeing the payment, may make use of derivatives and other financial instruments to insulate the return. In both cases there is a cost associated with removing variability in investment return, although the annuity provider is likely to be able to do this more cheaply on a wholesale basis, rather than retail.

Someone using draw down may prefer to take a higherrisk approach, usually taking professional financial advice. Annuity providers could offer an annuity which varies with the movement in some index fund, but this is not available in New Zealand, and not understood to be widely prevalent elsewhere.
Clearly, maintenance of an assured level of income (or equivalent goods and services) is possible under draw down if there is an effective contract between the retired person and their heirs that, on early death, the heirs benefit through a bequest; but if life is prolonged, the heirs are obliged to find resources to continue support. Effectively the heirs are taking on the longevity risk in an informal (and legally unenforceable) fashion. ${ }^{5}$

For those, however, for whom such a contract is not possible, or appears too risky, the presence of a functional

5 Pigott et al. (2004) refer to a paper by F. Hayashi, J. Altonji and L. Kotlikoff (1996), 'Risk-sharing between and within families', Econometrica, 64, pp.261-94, which shows that risk-sharing through transfers is limited even within families. 
Figure 1: Comparison of annualised real return from draw down and annuity

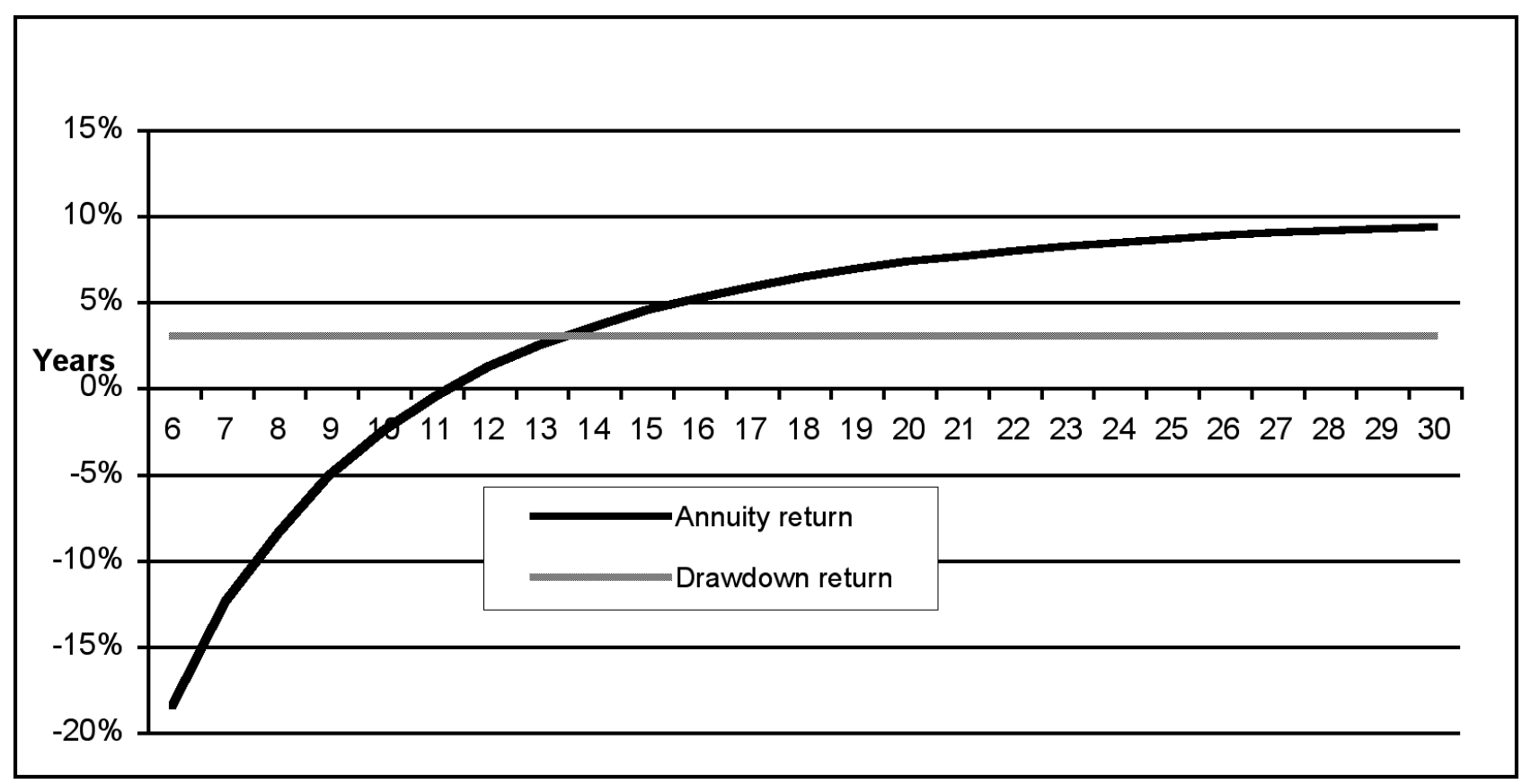

longevity insurance market would seem important. The comparison over time of the actual return from draw down with purchase of an annuity presented in Figure 1 gives emphasis to this. Here a level real return of 3.5\% per annum from draw down is compared to the annual accumulated return to a survivor under an annuity priced on the same return on the backing investments. (New Zealand life tables 2000-2002 All Males mortality is assumed; the expectation of life is about 17 years.)

On death within the first 11 years, the annuity purchaser receives a negative return on their investment. At 13 years, however, some four years before the median expected period of survival of 17 years is attained, the annualised return matches that for the draw down. An increasing average return is obtained thereafter for each further year of survival - 3\% per annum more already by the 17 -year point. The initial negative return may appear unattractive; but if one has died, this is of little consequence, while if one survives, the markedly greater return is obvious. ${ }^{6}$

Wakeling and Yang (2000) make this point in another way, demonstrating that even the most economically efficient form of draw down is around 30\% less efficient

6 These results are relatively insensitive to the assumptions made. than annuitisation in terms of effective utilisation of capital set aside to provide income in one's retirement. One should also note there is further risk inherent in draw down not captured here, not just the possibility of greater transaction costs, but the exposure to family pressure and potential fraud because of the flexibility of access to one's capital.

\section{Longevity insurance examined}

Having demonstrated the significant theoretical advantage of annuitisation over draw down, the question then is why is there not greater demand, and greater supply. To respond to this, it is useful to first illustrate how longevity insurance works.

This is done here by an example of pooling of longevity risk on a collective basis (i.e. without a guarantor). An initial cohort of 1,000 male 65 year olds is assumed to contribute $\$ 100,000$ initially to an annuity-paying fund. An investment return of $3.5 \%$ per annum real is assumed over the period, net of all expenses, and pricing is assumed to allow for increases of $2 \%$ per annum in line with anticipated price inflation. Finally, it is assumed that mortality will be in line with the New Zealand life tables 2000-2002 All Males table. The initial amount of pension is broadly of the order of $\$ 9,000$ per annum. 
Figure 2: Pension amounts by attained age, 20 simulations of 1,000 entrants, table AM(C)

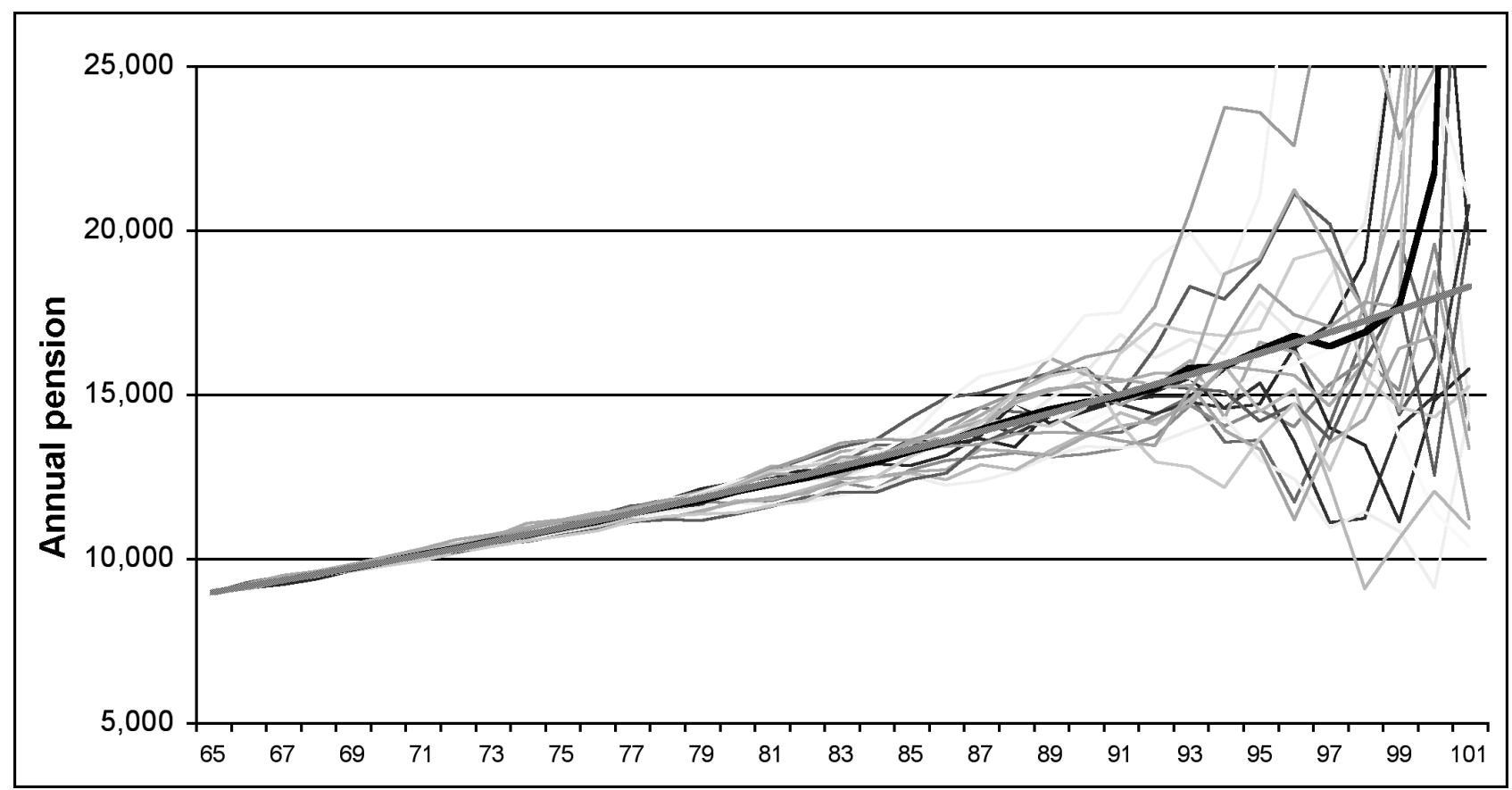

Twenty simulations are run to derive a series of stochastic outcomes within the expected probability distribution. In this exercise, it is assumed pensions are re-balanced at the end of each year. At each balance date after commencement, each surviving member has an asset share calculated, being the asset share at the start of the year, decreased by own pension payments and the share of tax and expenses, and increased by the share of investment return and 'fall-in' from deceased members. This asset share represents the relative interest of continuing members. The pension supported by the asset share is then obtained by repricing on the original pricing assumptions, allowing for the further year of age.

The first chart, Figure 2, shows outcomes assuming all participants are subject to the same force of agerelated mortality. There is a reasonable degree of closeness of outcome over the first 10-15 years, but then results become more variable as the number of survivors falls. After 25 years of operation - i.e. by age 90 - results become quite variable. In this example no pension actually falls until around age 87 , but around half have increases less than that assumed in the pricing basis.

The heavy black line shows the average over the 20 simulations, and the heavy grey line the expected result. In this example it will be seen that over these 20 simulations the average is close to the expected until very near the end, after age 98 .

To illustrate the effect of participants being admitted into this arrangement with mortality prospects different from the assumed risk, Figure 3 shows the results of 20 runs where $90 \%$ have the mortality on which pricing and re-pricing is based, while $10 \%$ have lower mortality (higher longevity), giving an extra three years' life expectancy at age 65 .

Initially, results do not depart greatly from those expected. However, after $5-10$ years the average starts to fall, reflecting the presence of some low-mortality participants who, as a result of not dying as quickly as assumed, cause asset shares to fall (since there are more survivors amongst whom the fund must be shared) and consequently lower pension amounts to be declared.

Eventually, the average pension amount over the 20 simulations (shown in grey) falls even below the expected level for lower-mortality pricing; this is because the mortality adopted for pricing purposes gives too high a pension and erodes the fund. 


\section{PolicyQuarterly}

Figure 3: Pension amounts by attained age, 20 simulations of 1,000 entrants, table AM(C) mixed with $10 \%$ low mortality

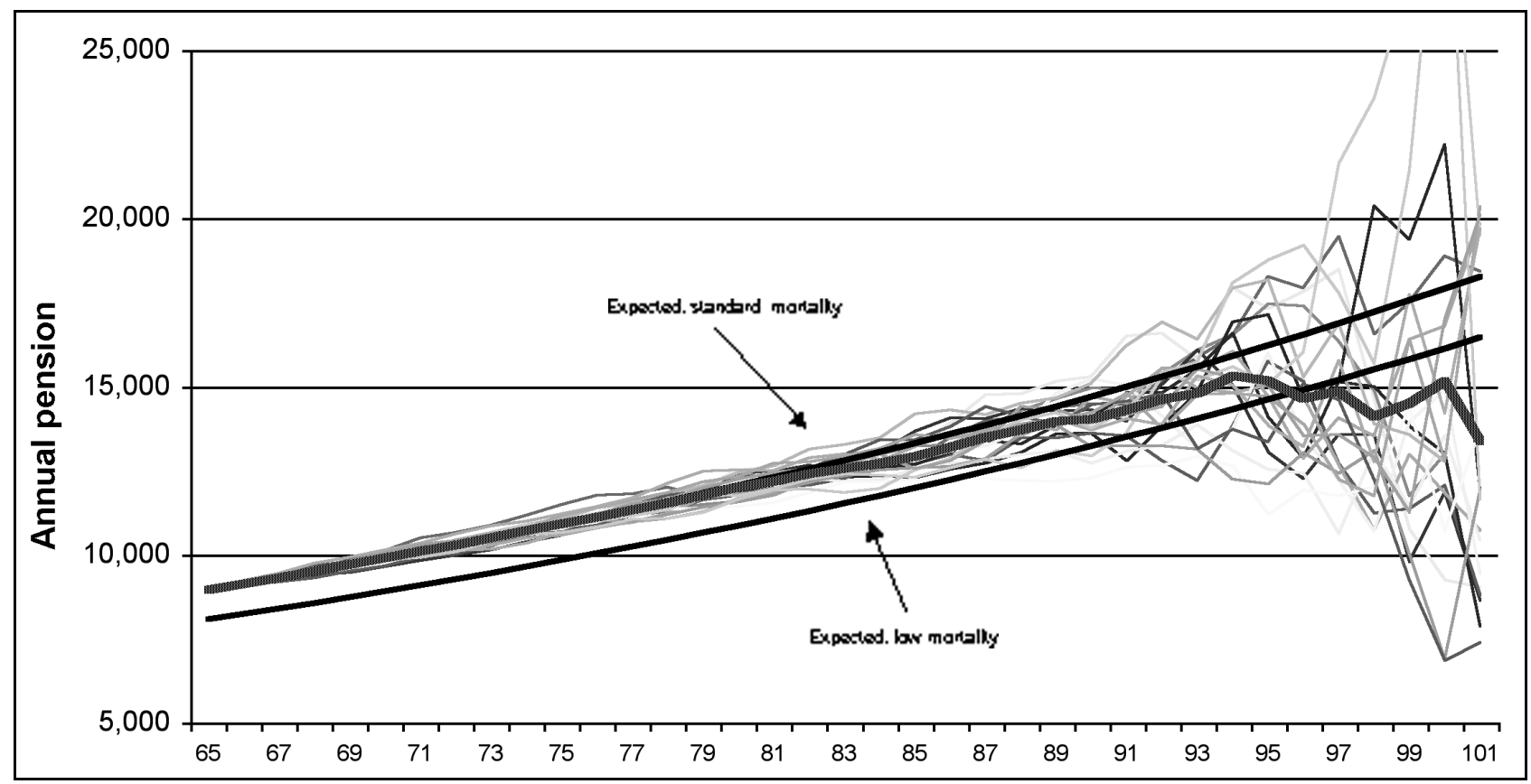

Figure 4: Pension amounts by attained age, 20 simulations of 1,000 entrants, table $\operatorname{AM}(C)$ mixed with $30 \%$ low mortality

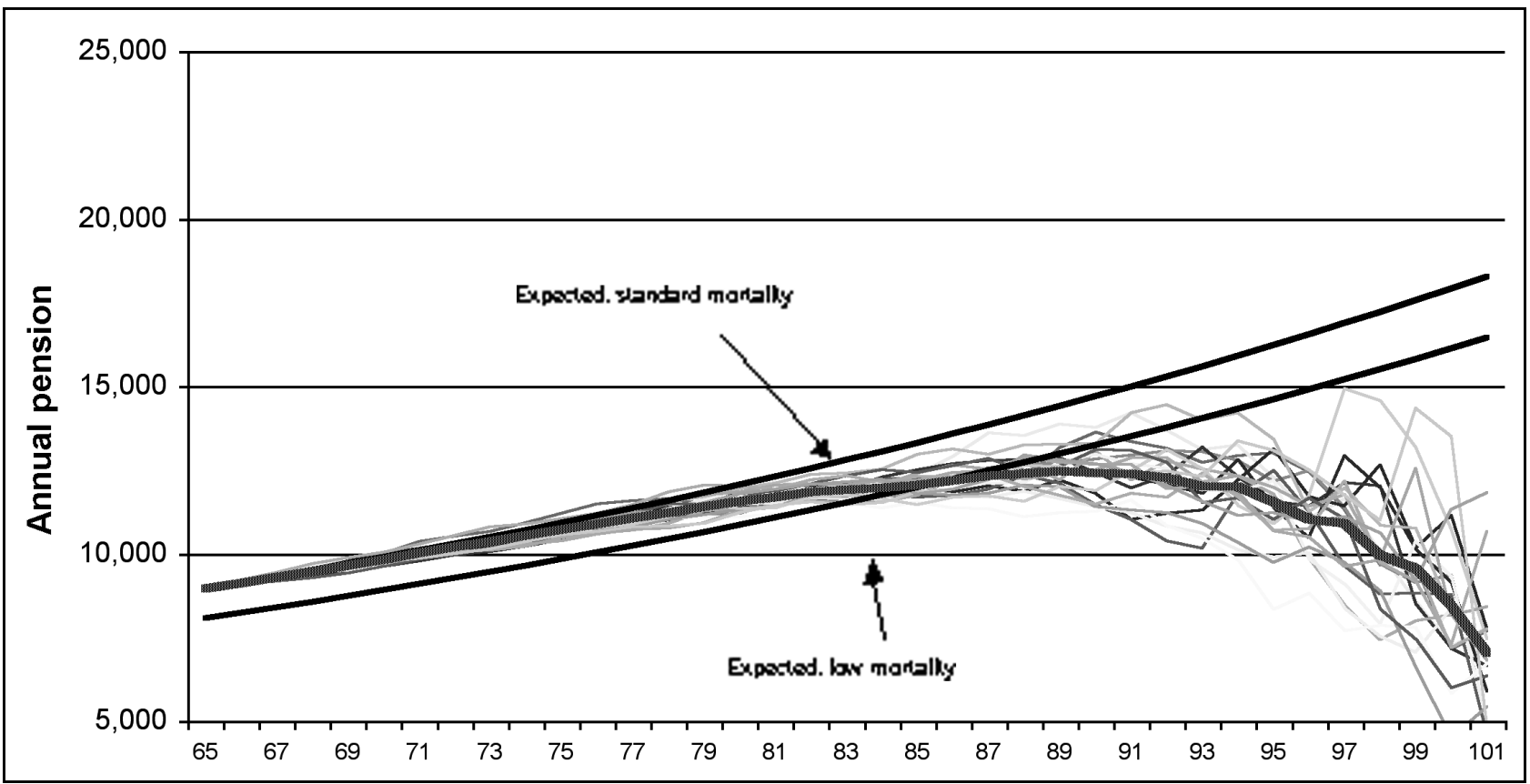


Figure 5: Pension amounts by attained age, 20 simulations of 1,000 entrants, table AM(C) mixed with $10 \%$ high mortality

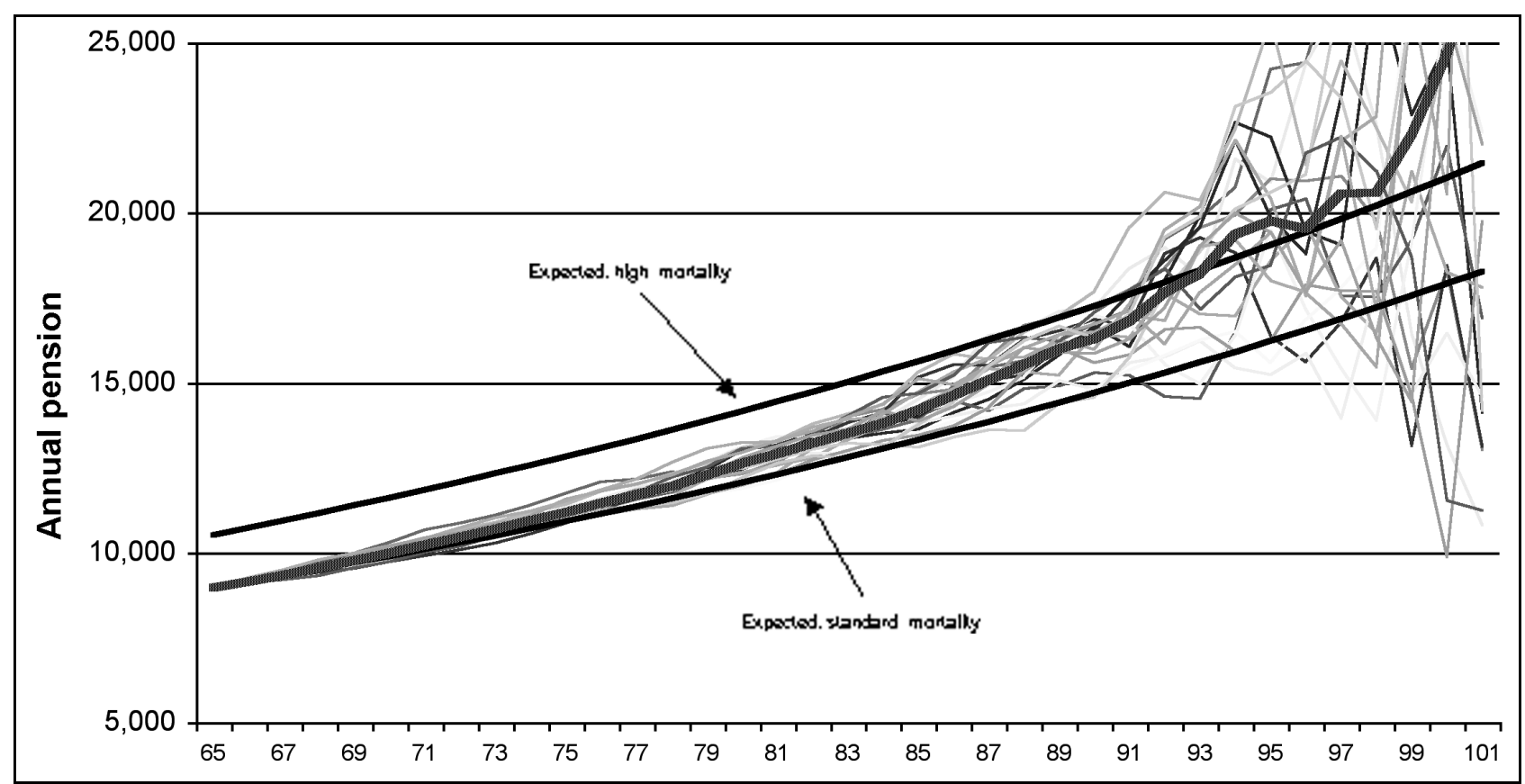

Figure 6: Pension amounts by attained age, 20 simulations of 1,000 entrants, table AM(C) mixed with $30 \%$ high mortality

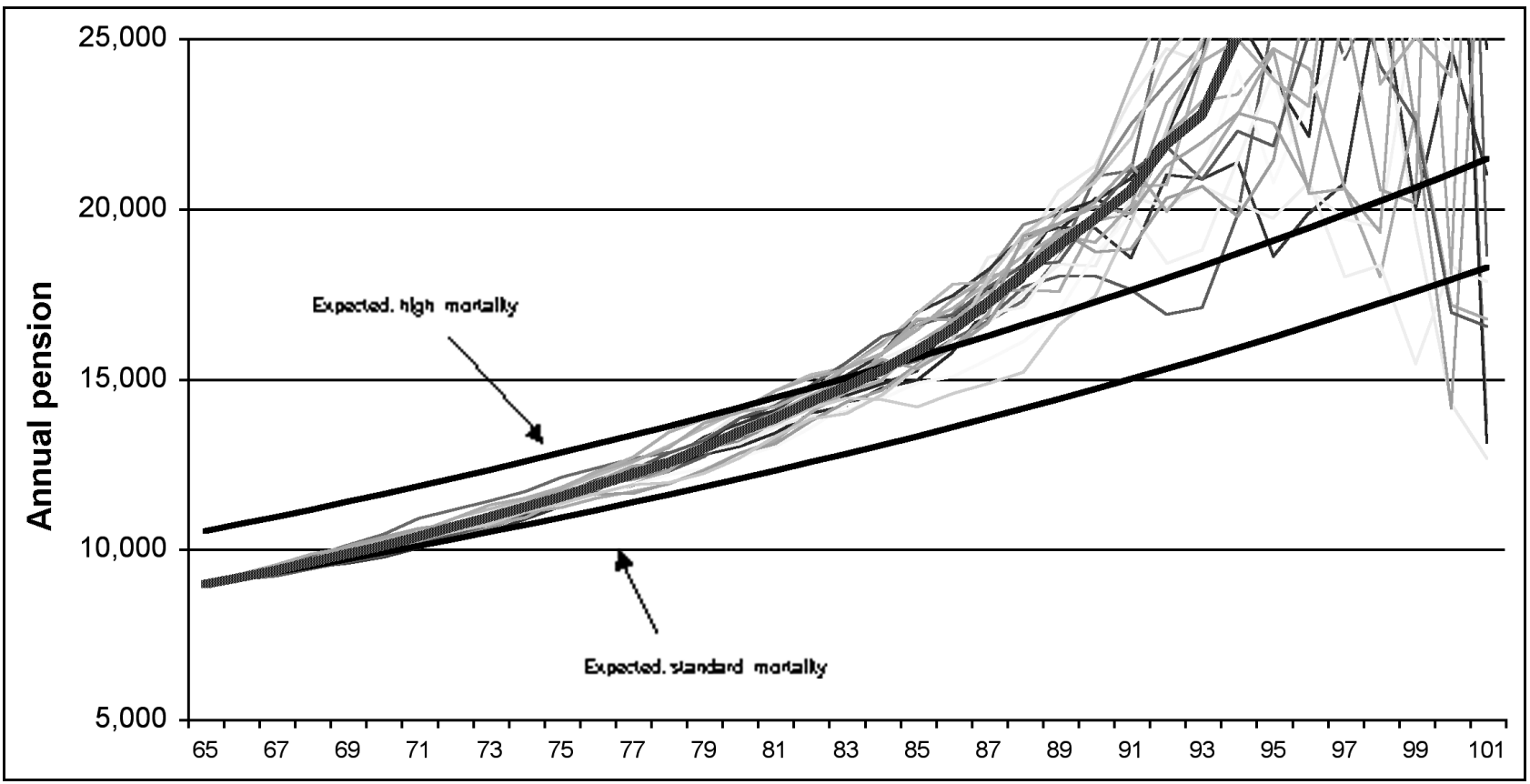


Figure 4 shows outcomes where 30\% rather than 10\% of the initial participants have lower mortality than that assumed.

Here the effect of over-provisioning - that is, re-pricing on the basis of mortality higher than would be expected by $30 \%$ of participants - is rather more marked, with the average falling faster. Note that the low-mortality group still initially benefit from participating, but will suffer erosion of the size of their pensions after age 85 unless the mortality pricing assumption is changed.

The next two figures, 5 and 6 , show the results where the minority participants have high mortality and hence lower longevity (around three years lower) than that assumed.

In the $10 \%$ case, the pension levels are only a little better than expected in the initial period, but after 10 years the effect of having more people than expected die causes the available funds to increase and higher pensions to become payable. The profits are eventually such, in these simulations, that survivors at the end receive pensions commensurate with what would have been payable under the high mortality assumption - although for 20 years, actual high-mortality participants will have had lower pensions than they would have expected.

Unsurprisingly, in the $30 \%$ case the impact of having a larger group of participants with higher mortality than assumed for the pricing leads to pension levels rising rather more sharply. The period for which the highermortality participants receive less than actuarially fair pensions is reduced to 15 years, but the actual numbers surviving past that time will of course be relatively few.

These illustrations demonstrate three particular features of longevity insurance for a guarantor such as a life insurance company.

- Even within a known mortality distribution there will still remain a good degree of variation if numbers of insured are relatively small. This idiosyncratic longevity risk, as it is termed, has to be catered for by the guarantor of the annuity, through reinsurance and/or holding capital fluctuation reserves.

- Good risk assessment and classification, known as underwriting, is essential. For the guarantor, the risk to be guarded against is people with mortality lower than anticipated; hence pricing tends to be based on the best lives. ${ }^{7}$
- If the mortality experience of the pool - i.e., the number of deaths - starts to diverge outside what could be anticipated from random fluctuations, this is a warning to (a) re-assess one's mortality assumption promptly for future contracts, and (b) set up loss reserves.

There is, in fact, considerable heterogeneity in mortality; refer, for example, to Blakely, Fawcett, Atkinson, Tobias and Cheung (2003), where disparity according to socioeconomic factors is identified in New Zealand. The absence of annuities priced according to appropriate rating factors, such as, for example, income, education, family history of mortality, smoking, etc, leads to what may well be perceived to be unfair results. It emphasises the results reported in some of the literature, that annuitisation which does not reflect reasonable perceptions of one's mortality risk will be seen as unfair and hence not utilised.

\section{The impact of systemic longevity risk}

Implicit in the simulation process used above is that there is an appropriate probability distribution for the expected mortality, and that the insurance problem is confined to idiosyncratic risk, i.e. random fluctuations. Unfortunately, there is now considerable doubt as to the rate at which future improvements in longevity will occur.

The problem is not that there are improvements; demographers and actuaries have incorporated estimates of longevity improvement in their projections for some time now. What has become evident in recent years, however, is that these projections have been wrong, and, of more concern, that there is no sound basis on which to forecast the future levels of improvement in a manner suitable for insurance. ${ }^{8}$ Cohort effects have been detected, but the drivers are not as yet understood. ${ }^{9}$ While some maintain that past levels of improvement

7 The extensive literature on annuitisation has mostly focused on a 'whole of population' mortality. The so-called 'annuity puzzle', relating to what appears to be a higher price for annuities than would be expected by reference to population mortality, is in fact explained by the fact that those who voluntarily purchase annuities generally expect to have better than average mortality - and life insurance companies price their products accordingly. Compulsory purchase of annuities required in the United Kingdom is, however, leading to the availability of underwritten 'impaired lives' annuities in that market.

8 Possible market solutions to the problems of insurance of this systemic longevity risk have been discussed; see, for example, Antolin and Blommestein (2007), and Blake, Cairns and Dowd (2006). These suggest that the problem of being unable to adequately quantify the risk remains a significant obstacle. 
will continue for the foreseeable future, others suggest, noting the rise of obesity and binge behaviours, that the improvement in longevity observed over the last century could level out or even reverse.

This uncertainty as to the future direction and extent of longevity improvement is referred to as systemic longevity risk. It applies in all developed countries, and is affecting the provision of annuities, since the risk is not hedgeable on financial markets.

\section{Policy issues}

The simple statement of the problem is that while longevity insurance through annuitisation presents marked theoretical advantages for the provision of regular income in retirement over the draw down alternative, it appears to be unattractive to those who might be expected to use it. The under-utilisation represents an economic loss which it is arguably desirable to try to mitigate.

The discussion in this paper so far has focused on the supply side issues around longevity insurance:

- managing idiosyncratic longevity risk: in the New Zealand market the small numbers are likely to result in a guarantor pricing only for the low-mortality group, as scale will not make it worthwhile to underwrite, and the guarantor will need to hold capital reserves (or completely reinsure), adding to the cost of provision;

- systemic mortality risk: as it is highly problematic to reinsure or to hedge this, potential providers may not wish to enter the market, or at the least will see a need to price conservatively, losing part or all of the comparative advantage over draw down.

Other supply side issues include investment and tax. As noted briefly, investment of the assets backing an annuity, if the payments are fixed, has to be in lowrisk instruments of appropriate maturities (to avoid reinvestment risk); in New Zealand, government bonds are relatively short-dated and hence not of enough length. It is also generally considered desirable for annuities to preserve purchasing power by being linked to price inflation, but inflation-indexed bonds are not available here. Whether the market could innovate by offering annuities linked to some replicatable investment index is a moot question.
Tax has not been mentioned. Briefly, taxation of annuity products in New Zealand is opaque, coming under life insurance company tax legislation. Ideally, the tax on the accrual of the earnings on investment of the backing assets would be neutral, but this would require a major rethink as to how annuities are provided (and taxed).

Turning to the demand side, the problems relate principally to the perceived lack of flexibility compared to draw down - handing over one's money for an annuity is rather final in that regard. A lack of trust in a lightly regulated financial services sector can be argued to be perfectly rational, given the complexity of longevity insurance; and the lock-in to low-yielding investments in return for a guarantee may not be well understood, nor easily explainable, given the product's lack of transparency. And perhaps one of the strongest factors affecting demand may be a sense of poor value for money if one is not in perfect health with long-lived parents, in the absence of any attempt to underwrite.

This analysis therefore suggests that even were there to be greater education as to the perils of not insuring longevity risk through buying annuities, it is unlikely that insurance companies would be able to provide annuities at a price that would be perceived as acceptable by the general population. Possibly, some employers might consider reverting to taking on some longevity risk for their employees by underwriting occupational pensions, but this seems only likely if there are sound labour market reasons for doing so.

\section{Policy responses}

One can identify three main policy options to address the current inability to obtain meaningful longevity insurance. ${ }^{10}$ These are:

- Do nothing, noting that New Zealand Superannuation provides at least a certain amount of longevity insurance, and that the greater retirement savings resulting from the KiwiSaver initiative may possibly lead in future to a market solution emerging without government involvement.

9 For a full description of New Zealand cohort mortality, refer to Statistics New Zealand (2006).

10 One could also consider making KiwiSaver proceeds available only as an annuity. Putting to one side the argument as to the merits or otherwise of this, the resultant annuity would still have to be provided in one of the three ways discussed here. 
- At the other extreme, have the state enter the market and establish a not-for-profit annuity fund offering CPI-indexed annuities. ${ }^{11}$

- As an intermediate position, consider facilitating the introduction of annuitised funds, under which participants self-pool their longevity and other risks on a collective and fully transparent basis.

If the argument is accepted that systemic longevity risk is not currently hedgeable, nor likely to become so in the near future, then a viable private annuity market under option 1 is unlikely - there is no sound basis for the private sector to accept the risk, except by charging prices that will deter most potential purchasers.

This will be particularly so when the disparity in expected mortality conditioned on such factors as income, gender, education, family history of mortality, smoking, etc is taken into account. Effectively, the potential insured population does not have the conventional single risk category (i.e. male or female) but a wider number of categories, implying a greater number of smaller risk pools. With a population the size of New Zealand's, any expectation of being able to hedge systemic longevity risk through private markets then becomes extremely small - even idiosyncratic longevity risk is difficult.

Options 2 and 3 would then seem more promising if New Zealanders are to have viable access to longevity insurance. But since the state is already providing longevity insurance through the state pension system at significant levels for those accustomed to lower incomes - although rather less so for the middle and higher income groups - it may be difficult to get acceptance of a state-supported annuity fund. Also, although longevity insurance would be addressed, this would not necessarily solve any of the other demand and supply side issues as noted above, were traditional annuity products only on offer.

There is, therefore, scope to explore whether option 3 , encouraging self-insurance through facilitating the introduction of annuitised funds, is worth consideration. As noted earlier, the basic features of annuitised funds are:

- self-pooling of longevity risk;

- self-pooling of investment risk.

11 Some might suggest indexing to net wage increases, as is done for New Zealand Superannuation; however, pricing of such annuities is highly problematic, if not impossible.
For a fuller discussion, Wadsworth, Findlater and Boardman (2001) provide an innovative introduction to the topic, and Daykin (2004) and Pigott, Valdez and Detzel (2004) expand on the theoretical aspects. The example given earlier in this article of re-balancing each year reflects the basic operational principles.

The annuitised fund certainly has a number of advantages compared to traditional annuity product, while retaining the economic advantage over draw down. Some of these are:

- The investment risk in annuitised funds is borne by the fund members. According to appetite for risk, this could permit greater holdings of growth assets in an annuitised fund than with a conventional annuity provider. Furthermore, there may be scope for individualised investment holdings, which would then allow someone to transfer their pre-retirement accumulated assets directly without incurring buying and selling costs.

- Tax of the income derived from investments could be tied to each participant's tax status, perhaps most efficiently by using imputation credits.

- The restriction on access to one's funds in traditional annuity products could be lifted to some degree, since the asset share of each participant is known (at least on balance dates). Actually permitting access would, of course, be conditional on the demonstration of continued good health, at the applicant's expense.

There do, however, remain some difficulties. A key outcome of an annuitised fund is spreading of longevity risk; a key concern is that risk be fairly borne by participants. Ensuring appropriate risk assessment for the pools would be essential, and require some resource put into research and setting national standards. Trusted regulation would also be needed.

The longevity insurance simulations also demonstrated that at older ages, when few are left in the pool, results become highly random. It may be that paying out participants at some age such as 95 would be desirable.

While in theory annuitised funds should absorb all idiosyncratic risk, there may be greater attractiveness were the state to at least provide stop loss insurance on a cost neutral basis; i.e. for deaths fewer than a certain lower limit the state would provide a subsidy, in return 
for a payment should deaths exceed a certain upper limit. This would be appropriate if, as suggested, the state sets the risk assessment standards.

As Antolin and Blommestein (2007) indicate, systemic risk will probably need to be absorbed to some extent by governments if longevity insurance is to flourish. Annuitised funds could either self-absorb systemic as well as idiosyncratic risk, subject to the stop loss insurance arrangement described above, or alternatively revise the mortality basis for re-balancing from time to time as and when it became apparent that the extent to which improvement in longevity allowed for in the mortality basis was out of line with up-to-date best practice. This latter arrangement would devolve the systemic risk completely onto participants; a quid pro quo might be a favourable tax treatment, or some other 'sweetener'.

\section{Conclusion}

This paper has made the argument that there is a clear theoretical advantage in utilising annuitisation rather than draw down from an efficiency perspective. In practice, in the current state of the market, traditional annuity products are not attractive, and, even with better education as to their merits, are unlikely to address the needs of those other than the very healthy, or with sufficient means to assure themselves of the very best health treatment. The 'do nothing' option is therefore rejected.

The option of the state stepping in to provide traditional annuity products is also rejected, on the grounds that the external guarantor model remains unworkable even were the state prepared to take on the systemic and idiosyncratic longevity risk on the grounds of market failure.

The option of facilitating self-insurance is shown to address a number of the disadvantages of traditional annuity products. There would, however, appear to remain a need for some state intervention, not least, it is suggested, a sound basis for assessing broad mortality risk categories, and some form of stop-loss insurance.

\section{References}

Antolin, P. \& H. Blommestein (2007) Governments and the Market for Longevity-Indexed Bonds, OECD Working Papers on Insurance and Private Pensions, No. 4

Blake, D., A.D.G. Cairns \& K. Dowd (2006) 'Living with mortality: longevity bonds and other mortality- linked securities', British Actuarial Journal, 12 (1)

Blakely, A., J. Fawcett, J. Atkinson, M. Tobias \& J. Cheung (2003) 'Decades of Disparity II: socioeconomic mortality trends in New Zealand, 1981-1999', Public Health Intelligence occasional bulletin 25, Wellington: New Zealand Ministry of Health

Daykin, C. (2004) 'Annuities and alternative ways of providing retirement income', IACA, PBSS and IAAust colloquium, Sydney

Munnell, A. \& M. Soto (2005) How Do Pensions Affect Replacement Rates, Center for Retirement research issue in brief 37, Boston

Pigott, J., E. Valdez \& B. Detzel (2004) 'The simple analytics of a pooled annuity fund', Journal of Risk and Insurance

Statistics New Zealand (2006) A History of Survival in New Zealand: Cohort Life Tables 1876-2004 Wellington

Wakeling, A. \& A. Yang (2000) 'Managing longevity risk', discussion paper, Australian Institute of Actuaries Financial Services forum 2001, Sydney

Wadsworth, M., A. Findlater \& T. Boardman (2001) Reinventing Annuities, London: Staple Inn Actuarial Society

Geoff Rashbrooke is a Fellow of the UK Institute of Actuaries, with a work background in life insurance and pensions, including spells as a consultant and as New Zealand Government Actuary. This article is drawn from a thesis submitted for an MCA at Victoria University of Wellington. Support for fees was provided by the author's current employer, the Ministry of Social Development. All opinions are, of course, the author's own. 